Jacek Mydla*

\title{
Performing Shakespeare's Words: Textual Authority in Light of the Theory of Indeterminacy
}

\begin{abstract}
On the basis of Roman Ingarden's conceptions of indeterminacy and concretization and the notion of spoken action, Jacek Mydla constructs the idea of textual authority in Shakespeare's drama. The text is regarded as the primary source of meaning which determines theatrical representation. When reading a play actively, the reader fills out areas of indeterminacy in an attempt to build a faithful imaginary representation of the action. The thus reconstructed social mimesis can then be transferred onto the stage. Mydla argues for the precedence of textual over theatrical concretizations of Shakespeare.
\end{abstract}

Keywords: indeterminacy; concretization (textual and theatrical); spoken action; social mimesis.

\section{Introduction}

Authority in performance comes down to the question of who decides what is to be happening on the stage? In the case of a Shakespeare play, the answer should be obvious: Shakespeare. Yet this is hardly an answer, for inevitably another question follows: Where is Shakespeare in, say, Hamlet? He is not one of the protagonists; nor does he appear on the stage to deliver a prologue or an epilogue. The only thing we have is the text of the play, or more accuratelya number of versions, none authoritative. But even assuming that we had an authorised version of Hamlet, the question would remain open: In what way and to what extent does the text of Hamlet authorise a performance? Behind all this lurks a theoretical issue: What makes a theatrical representation faithful? Can we assume that the text of a play has authority when it comes to the business of staging? If so, where does this authority lie?

My main goal in this article is to examine the idea of authority in performance from the perspective of two premises. One regards Shakespeare's plays as examples of spoken drama. According this textualist approach, the text

* University of Silesia, Poland. 
of the play determines theatrical representation. ${ }^{1}$ As the primary source of meaning, the text can and should be referred to in order to determine what takes place on the stage. ${ }^{2}$ The other premise comes from Roman Ingarden's theory of the literary work of art and concerns the idea of indeterminacy. ${ }^{3}$ In its general formulation, indeterminacy posits that fictive reality is never fully determinate; textually created objects never attain the full determination characteristic of real things; fictional and imaginary objects have gaps. ${ }^{4}$

Two distinct levels of indeterminacy need to be taken into account. In their textual state, i.e. as in a book, objects lack a great number of properties. The reader's imaginative interaction with the work fills some of them out, thus producing what Ingarden calls concretization. Yet also these mental objects are to a large extent indeterminate when compared with their theatrical equivalents.

1 Manfred Pfister, who himself consistently builds his theory of drama on this premise, traces the insight back to Pirandello's azione parlata (Pfister 6). Like Pfister, we shall also support this insight with the idea of performative language: "Since dramatic dialogue is spoken action, each individual dramatic utterance does not just consist in its propositional expressive content alone, but also in the way it is itself the execution of an act-whether in the form of a promise, a threat or an act of persuasion etc. Therefore, the performative aspect described by speech-act theory is always present in dramatic dialogue" (ibid.).

2 Opposed to the literary, or textual, conception of drama is the theatrical conception, which regards the stage and non-verbal happenings as the main source of meaning and largely independent of a text. This approach treats the text as subservient to the nonverbal content of the performance.

3 Polish phenomenologist Roman Ingarden (1893-1970) formulated his conception of the literary work of art as a refutation of Edmund Husserl's idealism. His focus is the ontological difference between products of the human mind and real things, between fictive objects and physical or mental entities. To describe this difference Ingarden uses the term "indeterminacy": while real objects are fully determined and have no gaps, fictive or imaginary entities are not. It is not possible to describe or exhaust the content of a physical object in a finite number of statements. Unlike the properties of real things, the properties of fictive object are founded in the statements describing them. In literary works, description equals creation.

In his book Das literarische Kunstwerk (1931), Ingarden describes the work of literature as a many-layered (stratified) entity or "formation: there are four layers: (1) word sounds; (2) meaning units; (3) schematised aspects; (4) represented objects. These form two double-layers: verbal (words) and mimetic (fictive objects): The main function of the literary work is to create an imitation of reality and to bring the reader into contact with it.

4 The verbal layer of a literary work makes determinate a finite and small number of properties of the objects portrayed therein. A few statements are true or false about Hamlet, e.g. "Hamlet is a student." Others, e.g. "Hamlet suffers from a heart condition," do not fall under the law of the excluded middle (i.e. they can be either true or false). Contrary to this, statements about real objects are always either true or false, because these objects have no "gaps." 
Thus the kind of Hamlet who is the product of my imagination when I'm reading the text of the play is greatly indeterminate when compared to the Hamlets whom we meet on the stage and in a film adaptation of the play. In this article, we will combine this insight with the first premise. The question is not what Hamlet looks like but what he is doing. The text of the play doesn't have much to say concerning the protagonists' physical appearance, but their behaviour is usually very well defined in the dialogues in which they participate. In a typical scene, we may not know (or wonder) what kind of pants Hamlet may be wearing or what colour his hair is, yet we know quite well what his mental state is.

We may say then that the text makes the readers concentrate their attention on some features of the character while it allows them to ignore others, the salient ones being those that belong to and represent spoken action. According to Ingarden's theory, both reading and theatrical performance are modes of reception and can be regarded as types of concretization. ${ }^{5}$ Both make a play "concrete" by filling out a number of gaps in the skeleton that is the literary work prior to its reception. The question of authority is then a question about justifiable concretization.

My main purpose in this article is, by using Ingarden's theory, to defend the idea of authority as a text-inherent quality. In order to do so we don't need to resurrect or exhume the long-dead author; we can do so but by redefining and vindicating the artistic autonomy of the literary text. My goal is not to deny the performance's right to offer an interpretation of a play; I will argue, however, that a self-conscious stage adaptation cannot not ignore the fact that the play is a carrier of meanings which a performance can faithfully represent.

I will illustrate the main points in my argumentation with reference to film adaptations of Hamlet.

\section{The poisoned cup sequence in Hamlet: textual and theatrical concretizations}

For illustrative material, I have chosen a critical moment in Hamlet. During the duel in the final scene, Gertrude decides to drink from the poisoned cup. This action is duly expressed, or "projected," in the lines of the dialogue. Here is the passage in a modern edition of the play:

GERTRUDE He's fat and scant of breath.

Here Hamlet, take my napkin, rub thy brows.

The queen carouses to thy fortune, Hamlet.

5 To avoid unnecessary complications, I ignore here the distinction between staging and performance. A staging in the sense of a general idea how to enact a play would be less concrete than any of its (that staging's) live realisations, or performances. 


$\begin{array}{ll}\text { HAMLET } & \text { Good madam. } \\ \text { CLAUDIUS } & \text { Gertrude, do not drink! } \\ \text { GERTRUDE } & \text { I will my lord, I pray you pardon me. [Drinks] } \\ \text { CLAUDIUS } & \text { [Aside] It is the poisoned cup. It is too late. } \\ \text { HAMLET } & \text { I dare not drink yet madam, by and by. } \\ \text { GERTRUDE } & \text { Come, let me wipe thy face. }\end{array}$

Let us try, like millions of readers before us, to establish what is going on here. To do that, we shall refer to the text and reconstruct the action on the basis of what the characters say. Following Ingarden's conception, we shall call this procedure the building of a concretization in the sense of a mental representation of the action as it has been projected in the dialogue. "What the characters say" means "what they say to one another," for scenes in drama mostly represent social interaction through dialogue. Claudius's aside is a notable exception, a moment in which what is spoken is not part of the ongoing exchange among the characters.

To answer the "What is happening?" question the reader uses her imagination. She may see herself watching a rehearsal of the scene and assume the point of view of the director or the actors. She may be asking these questions: What is happening when this line is spoken? How is this line spoken? What is happening between these lines? In a modern edition of the plays, some basic answers are given in the form of stage directions, but, as the above example shows, these are very sparse and possibly redundant. Besides, the earliest editions did not have them, as this quote from the 1623 Folio edition testifies: ${ }^{6}$

Qu. He's fat, and scant of breath.

Heere's a Napkin, rub thy browes,

The Queene Carowses to thy fortune, Hamlet.

Ham. Good Madam.

King. Gertrude, do not drinke.

$Q u$. I will my Lord;

I pray you pardon me.

King. It is the poyson'd Cup, it is too late.

Ham. I dare not drinke yet Madam,

By and by.

Qu. $\quad$ Come, let me wipe thy face.

These "original" editions could do very well without explicit stage directions for a good reason: the dialogue contains suggestions about what is happening when the lines are spoken (and around these lines, as it were). These

${ }^{6}$ http://internetshakespeare.uvic.ca/doc/Ham_F1 (accessed 2018-03-27). 
happenings are the many actions performed by the characters participating in the situation. Many of the lines are direct or implicit stage directions and as such are units of action. When Gertrude says, "The queen carouses to thy fortune, Hamlet," the line contains an explicit stage direction, which makes "[Drinks]" redundant and explains why we don't have it in the Folio edition. More importantly, a great many other stage directions would be needed to flesh out the dialogue, as it were, with action. Let us see what these could be:

$\begin{array}{ll}\text { GERTRUDE } & \begin{array}{l}\text { He's fat and scant of breath. [Looks concerned seeing Hamlet } \\ \text { gasping for breath] }\end{array} \\ & \text { Here Hamlet, take my napkin, rub thy brows. [Hands Hamlet } \\ \text { her napkin] } & \text { The queen carouses to thy fortune, Hamlet. [Picks up and } \\ \text { raises one of the cups] } & \text { Good madam. [Bows in gratitude] } \\ \text { HAMLET } & \begin{array}{l}\text { Gertrude, do not drink! [Looks and sounds alarmed] } \\ \text { CLAUDIUS }\end{array} \\ \text { GERTRUDE } & \begin{array}{l}\text { I will my lord, I pray you pardon me. [Drinks and then offers } \\ \text { the cup to Hamlet] } \\ \text { CLAside] It is the poisoned cup. It is too late. [Expression of } \\ \text { horror] }\end{array} \\ \text { HAMLET } & \begin{array}{l}\text { I dare not drink yet madam, by and by. [Gestures the } \\ \text { proffered cup away] } \\ \text { Come, let me wipe thy face. [Wipes Hamlet's face with her } \\ \text { napkin] }\end{array}\end{array}$

These stage directions may be read as a reader's thoughts when building a concretization on the basis of the dialogue. The reader converts the words into characters' actions as though taking place on an imaginary stage. ${ }^{7}$ In the terms of Ingarden's theory, the reader passes from the verbal meanings to their counterparts, i.e. the fictive objects. Here this means going from (or through) the lines to the protagonists and their actions, and from the dialogue to the dynamic situation. Any active and immersive reading means interacting with the mimetic layer of the work; it compels the reader to enact imaginary staging. The product of this operation is what we've called textual concretization. Compared to the

\footnotetext{
${ }^{7}$ Here are some of the formulations used by Ingarden to describe the difference: in passive reading "there is no kind of intercourse with the fictional objects." The reader does not "transpose oneself [...] into the world of the objects in a work [...]." In active reading, "one not only understands the sentence meanings but also apprehends their objects and has a sort of intercourse with them" (Ingarden, The Cognition, 38-39). When we read actively, "we project ourselves in a cocreative attitude into the realm of the objects determined by the sentence meanings. The meaning in this case creates an approach to the objects which are treated in the work" (40).
} 
skeletal or sketchy situation in the text itself, the scene as "staged" in the mind of the reader is concrete: the most significant gaps have been filled out; we know what's going on. At the same time, many gaps still need to be filled out. For instance, we may "see" Gertrude putting the cup to her lips, but we don't see the circumstances which have to accompany that particular action: Where does she take the cup from? Which hand does she use? Is she seated or standing up?

It is very convenient to translate, as it were, the places of indeterminacy into specific questions. As we soon realize, we can go on forever asking them: What is Hamlet's posture when Gertrude makes her comment? What does her napkin look like (its shape, its colour, etc.)? Where does she take it from? Who is she speaking to: Claudius? Osric? the whole crowd? Maybe she's speaking to herself? What is she doing when she is saying the line? - and many many more. Any actual performance brings answers to these, for any actual performance fills out areas which a textual concretization has left in a state of indeterminacy.

Below is an example of the filling out of gaps in an adaptation. This is the cup in the BBC Hamlet:

GERTRUDE He's fat and scant of breath. [Looks concerned seeing Hamlet out of breath, speaks this to Claudius, rises from her seat next to him, and walks briskly towards Hamlet]

Here Hamlet, take my napkin, rub thy brows. [Pulls a white napkin from her bodice and hands it to Hamlet; Hamlet, leaning against a table, wipes his face]

The queen carouses to thy fortune, Hamlet. [Picks up the cup from a tray]

HAMLET Good madam. [Line left out]

CLAUDIUS Gertrude, do not drink! [Looks alarmed, but controls his voice; manages to remain calm, face still smiling, keeping up the appearances]

GERTRUDE I will my lord, I pray you pardon me. [Drinks and then offers the cup to Hamlet]

CLAUDIUS [Aside] It is the poisoned cup. It is too late. [Whispers under his breath]

HAMLET I dare not drink yet madam, by and by. [Gestures the cup away]

GERTRUDE Come, let me wipe thy face. [Picks up the napkin again and wipes Hamlet's face]

We need to ask now about the significance of the theatrical concretization. Does this filling out of the gaps alter the progress of the action as represented in the textual concretization? Theoretically, there are two possible answers: 1 . The theatrical concretization does not affect the action; 2. The theatrical concretization in some significant manner changes the action. In other 
words, the difference between the textual and the theatrical concretizations may be one of degree (the progress being one towards greater determinacy), or it may be one of quality, in the sense of affecting the course and meaning of the action (by going beyond what is prescribed and projected in the dialogue). It is of course possible that in building the theatrical concretization the artists go beyond the suggestions of the text. The question is, can they do this without altering the text? If so, this filling out of gaps does not impinge upon textual authority, and consequently there is no discrepancy between the textual and the theatrical concretizations. On the contrary, the performers will be applauded for their competence and skill in enriching our understanding of the text of the play.

During an examination of the text of the poisoned cup sequence, some specific questions may occur to the reader, questions about motivation. Why does Gertrude want to drink in the first place? Does she know that she is going to drink from the poisoned cup? Answers to these questions bestow meaning on the sequence and the entire scene. While the text gives no answer to the first question; in the case of the other, the text seems mute. Gertrude wouldn't offer the cup to Hamlet, unless of course she wanted to poison him. But we know that she not aware of the Claudius-Laertes conspiracy to kill Hamlet. Most importantly, we know that she loves her son. So, if she knew the cup was poisoned, why would she do the villains a favour and almost become their instrument, by offering it to Hamlet?

Yet how do we know that she is offering Hamlet the cup in the first place? We can deduce this from his reply; otherwise his refusal to drink, would not make sense: "I dare not drink yet madam, by and by." As we can see, the text fails to answer some very basic questions, and thus also in a theatrical concretization some of them may remain unanswered. The BBC adaptation is faithful to the letter of the play: to its textual concretization, yet there still is a degree of indeterminacy as far as the main drift of the action is concerned.

Let us examine for contrast how the sequence has been handled in Laurence Olivier's 1947 film adaptation, in which the poisoned cup and Gertrude's decision to drink from it are placed in the foreground of the viewer's attention. Below is a reconstruction of the sequence on the basis on this adaptation. It will be noted that preceding this exchange the camera zooms in twice and for considerable lengths of time on Gertrude's face. We observe her growing certainty that the cup that's been offered to Hamlet contains poisoned wine. Her decision to drink springs from this certitude, which comes to dominate the entire sequence:

GERTRUDE He's hat hot scant of breath.

Here Hamlet, take my napkin, rub thy brows. [Remains seated, gives napkin to a servant, picks up the cup and drinks]

CLAUDIUS [Cries out in horror and gestures violently to stop her] Good Gertrude, do not drink! 


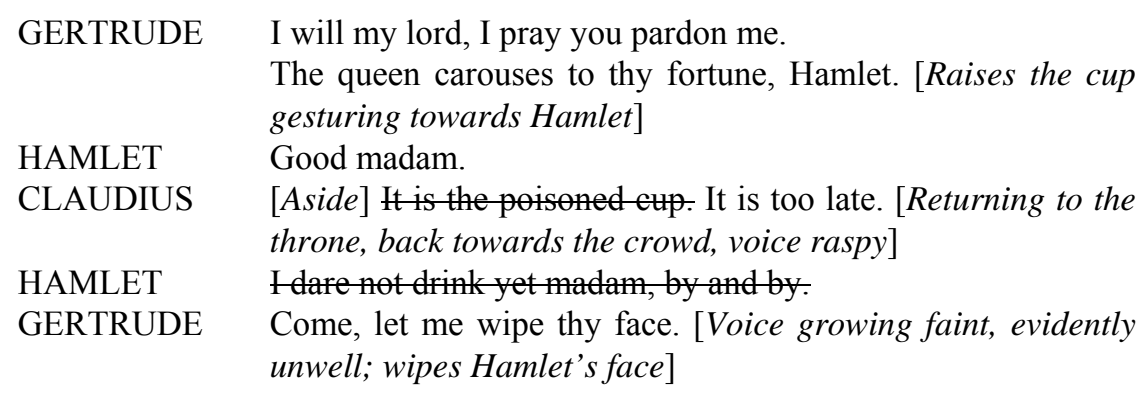

The two moments of silent concentration on Gertrude's face introduce a new meaning to the sequence, and this meaning becomes its dominant motif. Not only is this meaning absent from the text, but it actually disagrees with the reader's textual concretization. (We may also note in passing that the device is filmic not theatrical: the theatre does not make it possible to single out a feature by making the spectator's gaze zoom in on it.) This explains why it has been necessary to change the text. It has been necessary to adapt the dialogue so as to make it fit the motivation. Now an overarching meaning has been bestowed on it: the scene shows Gertrude's laying down her life to save her son.

Olivier's adaptation is an example of a theatrical concretization which impinges upon textual authority. The artists have decided to confer upon the sequence a meaning which not only does not arise from a reading of the text but simply one which disagrees with textual meaning. To be sure, a gap concerning Gertrude's motivation has been removed, but the price for this "amendment" has been the altering of the text so that it would fit the new idea. This new idea is not Shakespearean in provenance but possibly Freudian, and indeed Olivier's interpretation is admirably consistent in its interest in the troubled relation between the mother and the son.

\section{The Relation of Action to Descriptive and Performative Language}

Let us clarify the main ideas introduced in the previous section before we return to the idea of authority.

To begin with representation, if we take for granted that, like all literary works, dramatic works represent fictive worlds, then the question that follows is: What is the characteristic feature of the fictive world in drama? To answer this, we cannot ignore dialogue as the essential mode of representation. Even as we make this obvious statement, we become aware of a complication: people engage in dialogue, not only to describe things or even to tell stories, but also to negotiate mutual relations. In a sense the duel in Hamlet is a fit non-verbal backdrop to a typical dialogue: negotiation and power struggle. Similarly, to the exchange of thrusts in the duel, there is a thrust-and-parry exchange: Gertrude 
decides to drink to Hamlet's fortune, and she persists regardless of Claudius's express wish that she shouldn't.

In spoken drama there is equivalence between action and language. Actions are equivalent to units of dialogue. Alternatively, units of dialogue project corresponding actions. When reading a dialogue, a reader reconstructs the dramatic situation as a series of onstage actions. To say that a play depicts something is to say that it offers a representation of social interactions. ${ }^{8}$ Unlike the non-human backdrop (e.g. Elsinore with its chambers, ramparts, etc.), which is static and relatively stable, this social reality is dynamic and subject to change. The so-called setting is of secondary importance.

As is characteristic of dramatic situations in general, utterances in the poisoned cup sequence concern relations between the protagonists rather than descriptively referring to the circumstances in which the dialogue is occurring. There is a great difference between Gertrude's "He's fat and scant of breath." and her refusal to obey Claudius's "Do not drink." in: "I will [drink], my lord, I pray you pardon me." While the former is a statement of fact, the latter is an expression of will, of Gertrude's decision to disobey the husband and the king. Even though we know what the relations between the protagonists are, nominally at least, we cannot help observing that those relations are far from fixed. On the contrary, they are subject to ongoing (re)negotiation. Thus, when telling (asking? begging?) Gertrude not to drink, Claudius makes a claim to authority and expects to be obeyed. To his surprise, Gertrude disobeys him. Even though their mutual positions seem to be well defined, they are not fixed and undergo a redefinition. This interpersonal dynamic is precisely what makes the relations between the protagonists dramatic. ${ }^{9}$

Before we return to the idea of spoken action let us examine briefly the type of language which is not strictly dramatic. The utterance in which Gertrude informs us that Hamlet "is fat and scant of breath" is a factual statement. This language is descriptive, and its function is that of conveying information. In practical terms, utterances of this kind are directives. They determine what is to be shown and how. Consequently, some element of the stage representation ought to answer to the description conveyed in the utterance. Thus, Hamlet is supposed to be a fat man, and, in this very moment, he is supposed to be breathing heavily. In the case of Olivier's adaptation, because the actor is not a fat man, the line has been changed to "hot." This change is not substantial in that the line remains mirror-like descriptive.

${ }^{8}$ Indeed, it is hardly possible to think of a drama that would not prioritise this type of portrayed reality.

9 Interpersonal relations on both the micro and the macro scales are political in the sense that all interpersonal relations are relations of power. 
Descriptive langauge is passive: its role is to portray reality, not to change it. But its passive nature is precisely why it is relatively unimportant in drama. It sets up a context for the action instead pushing the action forward. In film adaptations of the plays, the camera saturates, as it were, the background with lush images, which may distract the spectator's attention from the dialogue. In the Shakespeare original, on the other hand, the setting is little more than a negligible backdrop and is commonly reduced to a few props, things which are important only to the extent to which they are used by the protagonists in the execution of their designs. The things that are brought into the foreground of the reader's attention are artefacts: the rapiers, the cup, and the napkin - these have a role to play in the duel scene in Hamlet, and the rest is of little consequence. Moreover, these artefacts remain in the corner of our vision (unless the camera brings them to the attention of the viewer-as is the case in Olivier's production). Still, objects are generic; their specific properties remain undetermined until an adaptation fills out the gaps.

The question arises, what authority does the text have over the descriptive content and the setting, props in particular? This question becomes interesting in adaptations which take liberties with semantics. Theoretically it is not impossible, without changing the original text, to make words refer to objects which do not fall into their usual semantic field, thus, for instance, updating the setting to make the play contemporary and possibly to attract more viewers. For instance, in Baz Luhrmann's Romeo+Juliet (1996) the word "sword," occurring regularly in the original, has been retained but is now used for a gun. How does this decision, this semantic shift, affect the text's authority? Has this authority been infringed upon? The answer-approval or condemnation - lies in the area of pragmatics and depends on the function which a particular descriptive unit and the relevant element of the setting play in particular scenes.

While descriptive language is passive and object-oriented, performative language is dynamic and oriented towards other people; it's dialogic. There are two basic types of performative language: conative and volitional. ${ }^{10}$ The conative use of language consists in getting another person to do something. For instance, in our short sequence, Gertrude tells Hamlet to "take my napkin" and to "rub thy brow" and Claudius wants to prevent Gertrude from drinking the poisoned wine by uttering a simple "Gertrude, do not drink." These utterances perform the conative function. The function is different in the line in which Gertrude, disobeying Claudius's injunction, expresses her determination to drink

${ }^{10}$ The so-called speech act theory distinguishes different types of performative utterances. Moreover, some scholars collapse the distinction between constatives (statements of fact) and performatives (speech acts). In my brief treatment here, I greatly simplify matters and regard as performative any utterances in which the function of advancing the action is the most obvious. 
after all. The language function here is volitional. Hamlet rejects her offer of the cup, saying "I dare not drink yet madam, by and by." All these are utterances in which a character expresses his or her decision to perform a certain action or to refrain from acting in a certain way.

To conclude: the portrayed world in a play is socially performed and essentially subject to changes and reconfigurations. There is a close correspondence between dramatic language and the type of reality this language builds and "represents"; the dominant performative language functions are, as it were, responsible for the fluid nature of the world of drama. The circumstances in which social interactions take place are little more than a passive backdrop, and therefore this is how its elements - such as the different artefacts used by the protagonists - are to be treated. Thus, it is of little consequence whether a particular artefact is a sword or a gun as long as it fulfils the role prescribed for it. In our Hamlet sequence it doesn't matter whether Gertrude drinks the poisoned wine from a glass cup or a coffee mug, for what really matters is the fact that she has decided to drink. In the larger context of the plot, this action - insubordination on the part of Gertrude - is an important step towards exposing the king's intrigue and bringing justice upon the guilty.

There is a great deal that the text does not determine, but it does determine what - in view of the essence of drama as spoken action-is essential, leaving all the rest to the imagination of the reader and the invention of the adapters. This, according to Ingarden's conception of indeterminacy, is the extent of the textual authority. Unless actors and directors intentionally wish to change the meaning of the play they're staging, they are obligated to enact the actions prescribed by the text. That said, we grant them a large scope of liberty when it comes to filling out those areas which do not affect the meaning fixed in a textual conretization. In other words, the text authorises those events which make up the social and interpersonal core of the plot. In the terms of Ingarden's theory, the text authorises any concretization that faithfully represents the play's drama. It is also here, in this quality of the dramatic, that we must look for a play's aesthetically relevant qualities. Having identified them, the practical question remains of how to bring the interpersonal relations into sharp focus and how to represent the dynamic of those relations.

\section{Authority and Faithfulness; the Verbal and the Mimetic}

According to the textual conception, a play is regarded as the template for its staging; what we have called textual concretization is to be seen as a necessary stage on the way to a faithful performance. The question which arises concerns the aesthetic criteria which follow from our considerations. Given our definition of drama, the values that actors and directors must pursue when staging a play 
ought to be those which inhere in the dynamic of human relations. In the last section of the article I propose to use the verbal-mimetic distinction to define the basic criteria for a faithful adaptation.

We seem to have ignored the poetic qualities of Shakespeare's language, precisely those qualities which make his plays unique. The poetry of the plays seems to be the main source of their aesthetic value, and thus also to deserve special attention in the theatre. To use Ingarden's terminology, a faithful performance ought to pay due respect to the verbal layer, i.e. the sounds and the meanings, and ought to bring to prominence the poetic qualities inhering in the sound and meaning formations in the text, or the manner in which Shakespeare has handled the musical and the semantic features of the words. It is common practice to retain the letter of the text despite the fact that the contemporary setting renders the words anachronistic, as is the case in Luhrmann's adaptation of Romeo and Juliet.

Such semantic clashes are unnecessary: there is nothing particularly poetic about the word "sword" which renders it aesthetically more valuable than "gun." What matters primarily is not the poetic qualities inhering in the word itself, but the manner it functions as an object in the dramatic situations in which Shakespeare has decided to use it. The mimetic layer as projected by the text takes precedence in this manner over the verbal layer. As we have argued, the category of the mimetic must be tuned to the specifically dramatic features of the portrayed reality. The primacy of the dramatic over the descriptive language has its equivalent in the primacy of interpersonal relations and their dynamic over the setting. It is the adapter's goal to prioritise characters over objects, the social mimesis over the still nature.

The source role and primacy of the text justifies this idea that a faithful performance should reproduce the social mimesis of the original: the world of the performance should correspond to that found in the play. The reader turned viewer should be able to recognize in the performance the world she has become familiar with when reading the play. Social mimesis thus becomes a directive with a number of practical consequences for the theatre and the film. Most significantly, a performance ought to retain the original set of characters and reproduce their mutual relations. Cutting out of characters and introduction of new ones must affect the integrity of the play and impinge on the authority of the text. Similarly, changes in the features constitutive of the identity of characters - skin-colour, age, gender, sexual orientation, and others-will affect social configurations, and the final result may be that of producing a new play, very different from the original. Finally, no new objects are needed, especially artefacts which participate in the action. On the other hand, semantic shifts are permitted, especially those that render the representation contemporary or domesticate it to the target cultural environment, provided that the objects retain the functions prescribed for them in the text. 
All the strictures just named are not to imply that the Shakespeare original ought not to be "tampered with" or to suggest that any departure from that original is an offence against the sanctity of the text and as such deserves nothing but condemnation. My point is simply to clarify what such departures mean and do, for without an understanding and delimiting of the scope of textual authority, we cannot even properly identify a departure from it as such. There is little doubt that many if not all values - i.e. aesthetically relevant qualities - can be detected in reading and captured in a textual concretization of a play. It is equally obvious that the plays only live in performance, while no reading, no matter how active, is able to animate their full potential. It is the actors' and the director's concern to make relevant to the audience their "animation" of a play.

I take it for granted that the aim of putting on another performance of Shakespeare is to engage the attention of the audience. The question is, is Shakespeare on his own enough to do so? Is it enough to show the poisoned cup scene without getting Gertrude to perform an act of self-sacrifice? Is it enough to show a duel without exchanging swords for guns? Is it enough to show a love triangle without making one of the men gay? Without being able to undertake here a thorough examination, let us posit that the principle of textual authority leads to the conclusion that representational faithfulness must take precedence over other concerns: aesthetic, social, political. As a rule, the text must be consulted - indeed, it must be read actively — before artists decide what is to happen on the stage. And this is usually the case: rehearsals customarily precede performance and silent reading precedes rehearsals. On the other hand, it is also common practice that a specific aesthetic conception, a "vision," is decided upon at the very start, that is, before the commencement of the staging process. This operative principle sounds more or less like this: "Let's see if we can make Shakespeare relevant to our contemporary audience." The silent assumption seems to be that on its own, and no matter how faithfully reproduced, the text will not engage a contemporary audience.

The idea of "making Shakespeare relevant" means that a performance addresses this or that issue, political or otherwise, and makes it dominate over the many small dramas which the individual scenes depict and which-as the centuries-long theatrical practice testifies - can be faithfully represented. Olivier's Hamlet may serve as an example of an adaptation with a high level of psychological consistency and aesthetic integrity. The film was made according to a vision and revolves around an interpretation of the main protagonist's condition as expressed at the very beginning, where Hamlet is described as "a man who could not make up his mind." A few lines from the play tell us how it is possible for one dominant vice to corrupt an otherwise healthy and noble soul. In this way a vision is suggested which in the play sums up the main antagonist, Claudius. In this bizarre decision Olivier may have been motivated by a desire to bestow some integrity on the intriguing protagonist of a notoriously 
ambiguous and many-dimensional play. On a much smaller scale, a similar idea seems to be in operation in the poisoned cup sequence. Gertrude is given here a noble unity of purpose, precisely the kind of motivation which at this juncture her character does not have. It is of course up to the individual viewer to decide if she likes this vision of Gertrude or not, and if so, what makes it relevant. Yet one thing is clear: we are no longer talking here about an adaptation of Hamlet in the strict sense of the word but about a film inspired by the play. Moreover, only a reader who has already built an adequate textual concretization will be able fully to appreciate the significance of such artistic decisions.

There are many different ideas and values that adapters may pursue, and faithfulness to the text may not be among the most favoured. Indeed, my impression is that customarily adapters labour under the obligation to sacrifice textual meaning to other concerns: social relevance, political topicality, psychological consistency, ideological correctness. From the perspective of textual authority, the difference between a Shakespeare performance (e.g. the BBC Hamlet) and a Shakespeare-inspired one (e.g. Olivier's Hamlet) is obvious. There is no law to make sure that an adaptation respects the authority of a Shakespeare text. On the other hand, there is a great of deal of insincerity and hypocrisy when the name of Shakespeare as a label is retained but a chopped-up text or a text otherwise rendered dysfunctional is served to the audience and used as an occasion to make topical statements. A healthy dose of respect for the shared cultural heritage and indeed a large degree of artistry are needed to make a staging Shakespearean.

To repeat: To defend textual authority is not to insist that there is one and one only proper way to stage Shakespeare and make a performance respectful towards the authority inherent in the text. On the contrary, the idea of indeterminacy makes it obvious that every play leaves a great deal of room for imagination and inventiveness. Loyalty to the social mimesis in Shakespeare ought not to be understood as dogmatic worship at the shrine of Shakespeare. On the contrary, there is so much that remains unspecified in the text and that actors and directors can and must recreate. There certainly is a great deal of compulsion in the scenes and sequences, but there is also much room for artistic ingenuity. Just as there is no hint in the text as to what is going on inside Gertrude when she's raising the cup to her lips, there are no directions about how to handle particular scenes and sequences. And there is no way to predict the audience's responses, or say in advance what this particular spectator will find relevant.

The idea and the primacy of textual authority does not annul or even substantially hamper artistic liberty. Indeed, it may be liberating to realise that there is such a thing as Shakespeare, a body of work which is not tied down to the claims of the here and now. The one obligation which the theatre ought not to forget about is its faithfulness to human drama. 


\section{Appendix: premises and rules}

\section{Premises:}

\section{The literary work}

1.1. The literary work is a product of the imagination; it is a representation of fictive reality.

1.2. Fictive reality has a foundation in the language which describes it; the properties of fictional objects are determined through the utterances which describe them.

1.3. Unlike real things (physical things, people), fictional objects have areas of indeterminacy ("gaps"): many of its properties are not given (many questions about them cannot be answered).

1.4. The literary work consists of two layers: the verbal (sounds and meanings) and the mimetic (objects).

\section{Reception}

2.1. In active reading, the mind passes through the verbal layer and grasps the objects portrayed in the mimetic layer.

2.2. Active reading fills out essential areas of indeterminacy, which makes possible imaginary intercourse with objects in the portrayed world.

2.3. The mental product of active reading is called textual concretization.

\section{Drama}

3.1. Drama is a representation of spoken action.

3.2. The main form of language in drama is dialogue: dialogue represents interaction between the protagonists.

3.3. There are two types of utterances: descriptive and performative; unlike descriptive utterances, performative ones affect the social reality represented in the play.

3.4. There are two types of performatives in drama: conative and volitional. These utterances perform the dramatic function, that of pushing the action forward.

3.5. The portrayed reality in drama is a social sphere of interpersonal relations. This is the essence of action in drama.

3.6. Action in drama is dynamic in proportion to the amount of performative language.

3.7. The portrayed reality in drama is not static (unlike its background) but dynamic: it is essentially negotiable.

3.8. To the extent that these relations are relations of power (authority, dominance, submission, etc.), this reality is political.

\section{Reception in drama}

4.1. There are two main forms of concretization: textual and theatrical.

4.1.1. Textual concretization is a mental (imaginary) staging constructed in an active reading of the text.

4.1.2. Theatrical concretization is any actual performance (on the stage or on screen). 
4.2. Textual concretization fills out the essential ("dramatic") areas of indeterminacy; theatrical concretization fills out secondary gaps.

4.3. Textual concretization is a reconstruction of a play's action.

\section{Rules:}

1. A theatrical concretization (a staging, an adaptation) respects the authority of the text if it preserves the meanings reconstructed in the textual concretization. To this degree it is faithful.

2. A faithful theatrical concretization ought not to interfere with the action as captured in the textual concretization of a play.

3. The dramatic function ought to be given precedence over the descriptive and poetic functions of language.

4. Social mimesis ought to be given precedence over the verbal layer of the text.

\section{WORKS CITED}

\section{Adaptations of Shakespeare}

Hamlet. Dir. Laurence Olivier. Film. Two Cities Films / Carlton International Media, 1948.

Hamlet. Dir. Rodney Bennett. BBC TV Production and Time-Life Television, 1996.

Romeo+Juliet. Dir. Baz Luhrmann. Bazmark Films and Twentieth Century Fox, 1996.

\section{Literature}

Ingarden, Roman. The Cognition of the Literary Work of Art. Trans. Ruth Ann Crowley and Kenneth R. Olson. Evanston: Northwestern University Press, 1973.

Ingarden, Roman. The Literary Work of Art. An Investigation on the Borderlines of Ontology, Logic, and Theory of Literature. Trans. by George G. Grabowicz. Evanston: Northwestern University Press, 1973.

Ingarden, Roman. "Z teorii dzieła literackiego." In Henryk Markiewicz, ed., Problemy Teorii Literatury. Vol. I. Wrocław: Zakład Narodowy im. Ossolińskich, 1987. 7-54.

Kuznicka, Danuta. "Ingarden on the Theatre." In Bohdan Dziemidok and Peter McCormick, eds., On the Aesthetics of Roman Ingarden: Interpretations and Assessments. Dordrecht, Boston, London: Kluwer Academic Publishers, 1989.

Mitscherling, Jeff. Roman Ingarden's Ontology and Aesthetics. University of Ottawa Press, 1997.

Shakespeare, William. Hamlet. Folio 1. 1623; at http://internetshakespeare.uvic.ca (accessed 16.03.2018)

Shakespeare, William. Hamlet, Prince of Denmark. Cambridge: Cambridge University Press, 2003.

Smith, Jadwiga S. "The Theory of Drama and Theatre: A Continuing Investigation of the Aesthetics of Roman Ingarden." In Anna Teresa Tymieniecka, ed., Roman Ingarden's Aesthetics in a New Key and the Independent Approaches of Others: The Performing Arts, the Fine Arts, and Literature. Ingardeniana III. Dordrecht, Boston, London: Kluwer Academic Publishers, 1991. 3-62. 